\title{
Imágenes que revelan sentidos: ventajas y desventajas de la entrevista de foto-elucidación en un estudio sobre jóvenes y escuela media en la Ciudad de Buenos Aires'
}

\author{
The meanings of images: advantages and disadvantages of \\ photo-elicitation interview in a study on young people and secondary \\ schooling in the City of Buenos Aires
}

\author{
Analía MeO \\ VALERIA DABENigno. \\ Facultad de Ciencias Sociales - Universidad de Buenos Aires \\ analiameo@sociales.uba.ar (ARGENTINA)
}

Recibido: 21.01 .2010

Aceptado: 18.01 .2011

\section{RESUMEN}

Este artículo examina el uso de una de las técnicas más difundidas en el contexto anglosajón dentro del repertorio de investigaciones con imágenes: la entrevista de foto-elucidación (EFE). Su uso ha sido marginal tanto dentro de la sociología argentina como iberoamericana. La EFE se caracteriza por incluir fotografías durante el transcurso de una entrevista con el propósito de favorecer el diálogo entre entrevistadores y entrevistados, y facilitar recuerdos y la expre-

${ }^{1}$ Analía Meo agradece el financiamiento del Economic and Social Research Council (Reino Unido) (PTA-026-27-2053) y del Consejo Nacional de Investigaciones Científicas y Técnicas (Argentina) durante la etapa de elaboración de este trabajo. Las autoras agradecen el financiamiento de la Universidad de Buenos Aires para la realización de esta investigación (proyecto UBACyT S836). También reconocen a sus colegas Patricia Salti y Soledad Vázquez su compromiso y dedicación durante la investigación. También agradecen muy especialmente a las autoridades de las escuelas, los docentes, preceptores, y estudiantes su permanente colaboración y buena voluntad. Finalmente, agradecen los comentarios críticos y constructivos de los evaluadores anónimos de este trabajo. 
sión de sentimientos y perspectivas. A partir de la experiencia de investigadores en Estados Unidos e Inglaterra y de los resultados de una investigación propia, se argumenta que la EFE puede enriquecer notablemente el estudio de ciertos fenómenos sociales -tales como las perspectivas de los jóvenes sobre la escuela y sobre sí mismos-, y se brindan elementos para una evaluación crítica de la EFE en estudios producidos en nuestras latitudes. En primer lugar, a partir de la revisión de literatura especializada anglosajona, se examina el alcance, limitaciones y ventajas de la EFE en investigación social. Seguidamente, se describe el uso de materiales visuales en la sociología argentina y se analiza una investigación desarrollada en Buenos Aires. Este caso permite ilustrar ventajas, desventajas y desafíos de la EFE, evidenciando características comunes al contexto anglosajón y otras específicas a sociedades en vías de desarrollo.

\title{
PALABRAS CLAVE
}

Investigación con imágenes, sociología visual, metodologías cualitativas, entrevista de foto-elucidación

\begin{abstract}
This paper examines the use of photo-elicitation interviews in the Anglo-Saxon and Argentinean contexts. While in the former, its use is extensive; in the latter, only few researchers have engaged with it. In this type of interview, researchers use photographs to prompt memories, feelings, stories and views from interviewees. Following the Anglo-Saxon literature and the assessment of one Argentinean study, this article argues that photo-elicitation interviews could notably enrich the study of certain social phenomena. Moreover, it offers tools to assess the use of this interview technique in Argentina and Ibero-América. The first section, following international literature, analyses the scope, limitations, and benefits of the photo-elicitation interview. The second section examines the use of visual materials in sociological research in Argentina, and the use of the photo-elicitation interview in one qualitative study carried out in the City of Buenos Aires in 2007. Here, the cons, pros and ethical challenges of the use of this type of interview are unfolded. This section demonstrates that the outcomes of the photo-elicitation interview supersedes the multi-layered complexities this technique involves.
\end{abstract}

\section{KEYWORDS}

Imaged based research - visual sociology - qualitative methods - photo-elicitation

EMPIRIA. Revista de Metodología de Ciencias Sociales. N. ${ }^{\circ}$ 22, julio-diciembre, 2011, pp. 13-42. ISSN: $1139-5737$ 


\section{INTRODUCCIÓN}

A pesar de que la vida social está fuertemente signada por lo visual, la investigación sociológica empírica se realiza y expresa fundamentalmente a través del texto escrito (Banks 2001; Prosser 1998; Rose 2006), tanto en el ámbito internacional como en Argentina. La palabra escrita asume un carácter dominante -y en la mayoría de los casos, exclusivo- en los modos de producir y presentar los resultados de las investigaciones. Aun cuando hay investigaciones que las incorporan, las imágenes asumen generalmente un carácter subsidiario, complementario y ad hoc (Becker 2002; Prosser 1998; Rose 2006). Prosser (1998), por ejemplo, sostiene que los «investigadores basados en palabras» conforman una ortodoxia dentro del campo de la investigación cualitativa que resulta poco permeable a la incorporación de imágenes en sus estrategias metodológicas y como medios de representación.

No obstante, durante las últimas tres décadas, tanto en Estados Unidos como Inglaterra se han desarrollado y consolidado comunidades académicas que utilizan imágenes estáticas y en movimiento como medios para explorar, indagar, representar e interpretar fenómenos sociales (Prosser 1998; Pink 2006; Wagner 2002). En el caso de la investigación sociológica hispanoamericana, la incorporación de las imágenes todavía es una materia pendiente (de Miguel y Ponce de León 1998; de Miguel 2003). En el ámbito específico de la investigación sociológica argentina -núcleo de interés de este artículo- se observa una tibia emergencia de estudios que usan materiales visuales en sus estrategias metodológicas (entre otros, Monchietti y Sánchez 2008; Pérez y Torricella 2005; Oubiña 2002; Vernik 2001; Meo et. al. 2005; Meo 2007). No obstante, este incipiente interés local no ha sido acompañado, hasta el momento, por análisis que examinen y reflexionen acerca de las posibilidades, límites y desafíos del uso de imágenes (estáticas y en movimiento) en investigaciones sociológicas concretas, salvo excepciones (Meo 2008).

Este artículo se propone contribuir a este debate. Para ello, examinará el alcance, limitaciones y ventajas de la entrevista de foto-elucidación (EFE) en investigación social en el contexto anglosajón. Seguidamente analizará cómo esta técnica ha sido utilizada en un estudio sociológico argentino, realizado en una comunidad académica donde el uso de materiales visuales es incipiente. Argumentará que la entrevista de foto-elucidación (EFE) puede constituirse en una técnica muy fructífera para la investigación social de ciertos fenómenos sociales. La EFE se caracteriza por incluir fotografías durante la entrevista con el propósito de facilitar la comunicación, evocar sentimientos, memorias y relatos por parte de la persona entrevistada.

Este trabajo se organiza en dos secciones. En la primera parte, a partir del análisis de literatura especializada de Estados Unidos y el Reino Unido, analizaremos el alcance, potencialidades y desafíos del uso de la entrevista de fotoelucidación (EFE). En la segunda sección, evaluaremos la implementación de la EFE en un estudio sociológico sobre la experiencia escolar de jóvenes de sec-

EMPIRIA. Revista de Metodología de Ciencias Sociales. N. ${ }^{\circ} 22$, julio-diciembre, 2011, pp. 13-42. ISSN: $1139-5737$ 
tores populares en la Ciudad de Buenos Aires, llevada a cabo por las autoras de este artículo.

\section{LA ENTREVISTA DE FOTO-ELUCIDACIÓN EN LA INVESTIGACIÓN SOCIOLÓGICA EN EL CONTEXTO ANGLOSAJÓN: ALCANCE, VENTAJAS Y DESAFÍOS}

Desde la década de los 70, en Estados Unidos y el Reino Unido, se evidencia un constante crecimiento de la producción sociológica anglosajona centrada en lo visual ${ }^{2}$. Numerosas investigaciones en distintas subdisciplinas (tales como la sociología de la salud, de la educación, del trabajo, de la infancia, y el cambio social) han incorporado materiales visuales como fuente y medio de producción de datos (entre otros, Bolton et. al. 2001; Campos Monteiro y Dollinger 1998; McGregor 2004; Mitchell y Weber 1998; Hareven y Langenbach 1978; Gates 1976). Films, videos, fotografías, comics, diagramas y dibujos han sido utilizados en una o más etapas del proceso de investigación (Banks 2001). En el caso de las fotografías, imágenes producidas por los sujetos entrevistados, álbumes familiares, y fotos de archivos han sido tomados como fuentes de datos o como disparadores de relatos y narrativas. Estas investigaciones basadas en imágenes se inscriben en enfoques epistemológicos discrepantes, tales como el positivismo, el constructivismo social y el paradigma crítico (Gold 1991; Prosser 1992; Banks 2001; Pink 2001). Asimismo, despliegan diseños de investigación muy diversos, en los cuales el estatus de las imágenes (estáticas o dinámicas) puede variar notablemente. En algunos trabajos, por ejemplo, lo visual adquiere un estatus subsidiario de lo textual y es presentado como una ilustración de lo analizado. En otros estudios, la unidad de análisis son las propias imágenes.

Dentro del campo de investigaciones basadas en imágenes, la entrevista de foto-elucidación (EFE) ha sido un técnica de producción de datos que ha generado numerosos adeptos (Kaplan, et al. 2007; Noland 2006; Rasmussen 2004; Thomson y Gunter 2007; Thomson y Gunter 2008). Este tipo de entrevistas utiliza fotografías como estímulo de la conversación entre la persona que entrevista

\footnotetext{
${ }^{2}$ Este mayor interés de la sociología en la IBI se expresa en: i) la configuración y crecimiento de redes internacionales de investigadores que los usan y evalúan sus potencialidades y límites (como, por ejemplo, «The International Visual Sociology Association», http://www.visualsociology.org); ii) la realización de congresos, seminarios y talleres internacionales en torno a la IBI (tales como las conferencias y talleres anuales organizados por la International Visual Sociology Association); iii) la creación de revistas especializadas en el uso de métodos visuales en investigación social (por ejemplo, las revistas académicas Visual Studies y International Journal of Visual Studies); y iv) la reciente emergencia de sesiones o mesas sobre métodos visuales en los principales congresos internacionales. Por ejemplo, el reciente congreso de International Sociologial Association (XVII ISA), propuso un grupo temático de Sociología Visual, interesado en reflexionar, entre otras cuestiones, en los efectos de las herramientas visuales en los entornos de investigación, en las relaciones entre tecnología visual y métodos de investigación, en la especificidad de los datos visuales frente a los orales y textuales y en los desafíos teóricos implícitos.
} 
y la que es entrevistada. Las fotografías se integran en este diálogo con el objetivo de provocar respuestas, interpretaciones, memorias, y sentimientos (Hurworth 2003). Asimismo, la inclusión de imágenes busca facilitar la comunicación y evitar la extrañeza inicial de la situación de entrevista (Hurworth 2003).

Las EFE pueden incluir imágenes producidas durante o con anterioridad a la investigación. En el primer caso, las fotografías han sido generadas para ser usadas en un estudio en particular. Éstas pueden haber sido tomadas por los/as investigadores/as, otros miembros del equipo de investigación, fotógrafos/as profesionales y/o por los propios sujetos investigados. Las EFE también pueden incorporar imágenes producidas por fuera de la investigación. En estos casos, por ejemplo, se utilizan como estímulos imágenes de archivos, fotografías de campañas publicitarias o revistas y documentales (Rose 2006). Las imágenes producidas en el marco de una investigación (ya sea por los que investigan o los sujetos participantes) tienen la ventaja de haber sido generadas en contextos y marcos significativos conocidos (o que pueden conocerse), lo cual podría enriquecer el proceso de producción y análisis de datos. En cambio, las imágenes producidas fuera de una investigación -en general- son acompañadas por pocos datos contextuales acerca de cómo y cuándo fueron tomadas, quiénes lo hicieron y con qué finalidad. En este sentido, la tarea interpretativa puede verse limitada o empobrecida (Prosser 1992).

En el contexto anglosajón, las EFE han sido utilizadas en numerosos estudios sociológicos de variadas áreas temáticas ${ }^{3}$. Así, por ejemplo, en sociología de la infancia y de la juventud, diversas investigaciones utilizaron EFE para explorar la vida cotidiana de los niños trabajadores (Bolton et. al. 2001) y en situación de calle (Campos Monteiro y Dollinger 1998; Young y Barret 2001). Otro ejemplo del uso de la EFE puede rastrearse en la sociología de la educación. En esta sub disciplina, la EFE se ha usado para estudiar la evaluación de los alumnos sobre el clima escolar (Schratz y Steiner-Loffler 1998), las relaciones espaciales y de poder dentro del aula (McGregor 2004) y la identidad profesional de la formación docente (Mitchell y Weber 1998). También en la sociología del cambio social se ha utilizado la EFE para examinar cambios residenciales (Hareven y Langenbach 1978) y actitudes hacia la modernización (Gates 1976).

A partir del análisis de investigaciones que utilizaron la EFE con imágenes producidas por los sujetos investigados, distintos autores argumentan que este tipo de entrevista favorece la expresividad y emotividad de los/as entrevistados/as; contribuye a relaciones de poder menos asimétricas entre entrevistadores y entrevistados; promueve la sorpresa de quien investiga (al brindar la posibilidad de que sean las personas entrevistadas quienes establezcan la jerarquía entre temas, escenarios y problemas); y el empoderamiento de las comunidades investi-

Este tipo de entrevista también ha sido extensivamente utilizado en la antropología (Pink 2001; Wagner 2000; Rodríguez Gutiérrez 1995).

EMPIRIA. Revista de Metodología de Ciencias Sociales. N. ${ }^{\circ} 22$, julio-diciembre, 2011, pp. 13-42. ISSN: $1139-5737$ 
gadas y enriquece la comunicación e interpretación de los datos (Kaplan et. al. 2007; Harper 2002; Galman 2009; Prosser 1992; Banks 2001; Wang et. al. 1996).

En cuanto a su capacidad para facilitar la expresividad y emotividad de los sujetos entrevistados, Harper (2002) afirma que la EFE se diferencia de la entrevista convencional en que la primera, al incluir imágenes y palabras, promueve la utilización de dos partes diferentes del cerebro (la que procesa la información visual es evolutivamente más antigua que la que tamiza la información verbal) y respuestas muy diferentes en las personas entrevistadas:

«las imágenes tienen la capacidad de evocar elementos más profundos de la conciencia humana que las palabras; los intercambios basados exclusivamente en palabras utilizan menos capacidad cerebral que aquellos intercambios en los cuales el cerebro procesó tanto imágenes como palabras»

(Harper 2002: 13).

Harper reconoce la capacidad de la EFE para promover la expresión de las emociones que circundan al acontecimiento o tema en estudio. Por un lado, las fotografías capturan (con mayor o menor éxito) las emociones y sensaciones de la persona que las tomó. Por el otro, las imágenes evocan reacciones emotivas, sentimientos, y memorias que difícilmente puedan ser generados en una entrevista tradicional (Harper 2002; Banks 2001).

Varios autores afirman que la EFE que utiliza imágenes producidas o provistas $^{4}$ por los sujetos investigados contribuye a un mayor involucramiento y reflexividad por parte de los entrevistados, otorgándoles así mayor agencia y control sobre la situación de entrevista (Hazel 1995; Harper 2002). Harper (1998), por ejemplo, señala que la EFE promueve un modelo de colaboración y relaciones de poder entre la persona que investiga y los sujetos investigados muy diferentes a los de la entrevista tradicional. En este tipo de entrevista, la agenda de lo que se habla tiende a estar regulada por los intereses prefijados por la investigación. En cambio, en la EFE el diálogo gira en torno a las imágenes producidas o brindadas por el/la entrevistada/o, las cuales establecen prioridades, jerarquías, y campos de sentido que deben ser explorados por quien entrevista. En la EFE, la persona entrevistada tiene mayor control sobre la interacción, los temas que se tratan y el orden en que estos se presentan.

Varios investigadores han señalado que las EFE contribuyen a un mayor entendimiento mutuo y confianza con los/las entrevistados/as (Hurworth 2003, Banks 2001), especialmente cuando se trabaja con poblaciones con las que es difícil comunicarse apelando exclusivamente a la comunicación oral (Epstein et. al. 2006; Wang et. al. 1996). Los autores mencionan a los jóvenes o niños, y a comunidades indígenas. En estos casos, las imágenes operan como «excusas» para que quienes son entrevistados compartan sus miradas y perspectivas. Ope-

\footnotetext{
${ }^{4}$ Por ejemplo, fotografías de archivo de la ciudad en estudio, de álbumes familiares, de archivos escolares, etc.
}

EMPIRIA. Revista de Metodología de Ciencias Sociales. N. ' 22, julio-diciembre, 2011, pp. 13-42. ISSN: $1139-5737$ 
ran como facilitadores del diálogo y de la interacción en un ambiente de mayor intimidad entre entrevistador y entrevistado (Banks 2001). Las fotografías tienden así un puente imaginario entre el mundo cultural del investigador y el del entrevistado (Harper 2002).

Otra ventaja de la EFE es la amplificación de las posibilidades analíticas del/la investigador/a en temas y perspectivas de análisis. En este último sentido, la inclusión de imágenes ofrece nuevo material para ser analizado, de manera conjunta o separada de los testimonios orales. En la mayor parte de las investigaciones con EFE se analizan tanto los contenidos de las imágenes como los testimonios de los sujetos investigados (Banks 2001, Rose 2006). Para la instancia de análisis de las imágenes resultan propicias las propuestas de autores que trabajan con análisis composicional (más allá de utilizar o no EFEs), identificando elementos constituyentes, actores, escenarios, símbolos y figuras presentes en las fotografías (Jewitt 1997, Rose 2006). Otros autores se centran en los testimonios de las entrevistas, concibiendo a las imágenes como estímulos centrales para generar relatos orales durante las entrevistas pero no necesariamente como objetos de análisis.

Asimismo, las posibilidades analíticas se amplifican porque las EFE que incluyen imágenes producidas o provistas por los sujetos investigados permiten descubrir dimensiones, temas, preocupaciones, intereses y perspectivas del fenómeno a estudiar que no habían sido considerados inicialmente por los/las investigadores/as (Bolton, et al. 2001; Hazel 1995; Holliday 2000; Mizen y OfosuKusi 2007). Así, la EFE puede contribuir al desarrollo de nuevos interrogantes y líneas de indagación (Bolton, et. al. 2001; Fischman 2001; Fischman 2002; Hazel 1995; Holliday 2000).

Asimismo, diversos autores afirman que el uso de la EFE en ciertas investigaciones colaborativas puede contribuir al empoderamiento de ciertas comunidades «vulnerables» (Hurworth 2003, Wang et. al. 1996). El mayor control que tienen los informantes sobre la situación de entrevista y los temas a tratar que ya señalamos (Hazel 1995, Harper 2002, Galman 2009) favorece este empoderamiento, aunque tal como argumentaremos más adelante, no lo garantiza por sí solo. Así también, la visibilización sobre sus condiciones de vida y necesidades, más aún cuando los sujetos investigados son quienes producen las fotografías, promueve la reflexión crítica y la deconstrucción de las propias asunciones (Harper 2002), y permite incrementar su conocimiento sobre cuestiones que les afectan cotidianamente y hacer públicas sus perspectivas y demandas (Wang, et al. 1996).

Las desventajas de las EFE no están tan desarrolladas como sus potencialidades en la literatura anglosajona revisada ${ }^{5}$. No obstante, varios autores descri-

\footnotetext{
${ }^{5}$ No obstante, hay una serie de argumentos críticos de la investigación basada en imágenes - campo más abarcativo que las EFE- realizada desde los textos clásicos de metodología cualitativa, que son ampliamente discutidos por Prosser (1998). En cambio, en el cuerpo del trabajo nos referimos a las desventajas identificadas desde los textos que bregan por el uso reflexivo de la EFE.
}

EMPIRIA. Revista de Metodología de Ciencias Sociales. N. ${ }^{\circ}$ 22, julio-diciembre, 2011, pp. 13-42. ISSN: $1139-5737$ 
ben limitaciones y recaudos que tuvieron en cuenta en sus propias investigaciones. Prosser (1992) reconoce que una limitación recurrente al trabajar con imágenes de archivo es la falta de información disponible respecto de las condiciones de producción y datos contextuales que permitan su interpretación, tales como cuándo y cómo se tomó, quién lo hizo o con qué finalidad. Prosser (1992) señala que, debido a estas limitaciones, las fotografías históricas son habitualmente utilizadas con otro tipo de evidencia textual. En la misma línea Banks (2001) señala que las fotografías que no fueron producidas por el investigador o que no tienen un vínculo directo con los entrevistados son raramente utilizadas en la investigación social por la limitación que provoca la falta de información sobre su contexto de producción.

En caso de producir las fotografías en el transcurso del estudio, se destaca como desventaja el alto costo económico comparado con otras técnicas de recolección (Karlsson 2001). La posibilidad de inconvenientes técnicos también es una limitación recurrente, que puede vincularse al tipo de equipos provistos (por ejemplo, Karlsson destaca la falta de cámaras con flashes lo suficientemente potentes para tomar buenas fotos de interiores); a fallas técnicas de las cámaras o a falta de nociones básicas para tomar fotografías por parte de los entrevistados (Mizen y Ofosukusi, 2007). Asimismo, Karlsson (2001) reflexiona sobre su propio estudio donde jóvenes estudiantes sudafricanos tomaban fotografías y señala dos desventajas potenciales que deben contemplarse: el abandono de los participantes como resultado de su fatiga o aburrimiento; y el riesgo de los estudiantes de ser víctimas de robos de sus equipos. Otra desventaja de las EFEs basadas en fotografías tomadas por los participantes, es la posibilidad de que las imágenes vayan más allá del foco de interés del estudio o no planteen una conexión aparente con el objetivo de investigación (Mizen y Ofosukusi 2007).

Finalmente, en términos de los desafíos éticos específicos de las EFE, varios autores afirman que sólo cuando los/as investigadores/as pensaban publicar las imágenes producidas por las personas entrevistadas tuvieron que tomar recaudos específicos (Wiles et al 2008) ${ }^{6}$. La promesa del respeto al anonimato del/a informante y a la confidencialidad de los datos, así como el pedido de su consentimiento para participar en el estudio alcanzan para cumplir con los principios éticos internacionalmente aceptados (British Educational Research Association 2004, British Sociological Association 2002) ${ }^{7}$.

\footnotetext{
${ }^{6}$ Cuando las imágenes de las EFE no fueron analizadas o publicadas, quienes investigaron no pidieron permiso a los/as entrevistadas para utilizarlas. En estos casos, los principios de consentimiento informado, confidencialidad y anonimato guiaron las interacciones con los sujetos investigados.

${ }^{7}$ La literatura anglosajona e internacional sostiene que, en el caso de algunas poblaciones particulares, como es el caso de los menores de edad, también deberá buscarse el consentimiento de los padres o tutores hacia el trabajo que demanda la investigación; asimismo, cuando hay instituciones involucradas en las fotografías - por ejemplo, una escuela- deberán solicitarse permisos a los directivos y demás involucrados (por ejemplo, los docentes si se tomaran imágenes de clases) (Meo 2010).
} 
Finalmente, en términos de los desafíos éticos específicos de las EFE, varios autores afirman que sólo cuando los/as investigadores/as pensaban publicar las imágenes producidas por las personas entrevistadas tuvieron que tomar recaudos específicos (Wiles et al 2008) ${ }^{8}$. La promesa del respeto al anonimato del/a informante y a la confidencialidad de los datos, así como el pedido de su consentimiento para participar en el estudio alcanzan para cumplir con los principios éticos internacionalmente aceptados (British Educational Research Association 2004, British Sociological Association 2002) ${ }^{9}$. Sin embargo, la publicación de fotografías producidas por los sujetos investigados vuelve problemática sino imposible el respeto al anonimato de las personas, lugares e instituciones involucrados (Clark 2006). En estos casos, los/as investigadores/as tienen que evaluar y sopesar distintos aspectos, tales como: los derechos de propiedad sobre las imágenes $\mathrm{y}$, centralmente, el conocimiento de los sujetos investigados respecto de cómo éstas serán diseminadas públicamente (Wiles et al 2008). La totalidad de los trabajos acuerdan en que los productores de las fotos son los propietarios de las imágenes. Asimismo, la mayoría de las investigaciones optan por presentar el material visual producido por los informantes o investigadores/as íntegramente, sin anonimizar a los individuos siempre y cuando cuenten con su consentimiento explícito.

En la sección siguiente examinaremos las ventajas, limitaciones y desafíos de una investigación cualitativa llevada a cabo en la Ciudad de Buenos Aires en el año 2007.

\section{EL USO DE LA ENTREVISTA DE FOTO-ELUCIDACIÓN EN UNA INVESTIGACIÓN SOBRE IDENTIDADES JUVENILES: ENTRE LAS PROMESAS Y LAS REALIDADES}

En Argentina, se está desarrollando lentamente un campo de investigación sociológica basada en imágenes. Indicadores de este proceso son el marginal número de artículos publicados en revistas de sociología; la existencia de jornadas, congresos especializados y el creciente número de ponencias en congresos. En cuanto a los artículos, en la Revista Argentina de Sociología (Monchietti y Sánchez 2008; Pérez y Torricella 2005) y en la revista Sociedad (Oubiña 2002; Ver-

\footnotetext{
${ }^{8}$ Cuando las imágenes de las EFE no fueron analizadas o publicadas, quienes investigaron no pidieron permiso a los/as entrevistadas para utilizarlas. En estos casos, los principios de consentimiento informado, confidencialidad y anonimato guiaron las interacciones con los sujetos investigados.

${ }^{9}$ La literatura anglosajona e internacional sostiene que, en el caso de algunas poblaciones particulares, como es el caso de los menores de edad, también deberá buscarse el consentimiento de los padres o tutores hacia el trabajo que demanda la investigación; asimismo, cuando hay instituciones involucradas en las fotografías - por ejemplo, una escuela- deberán solicitarse permisos a los directivos y demás involucrados (por ejemplo, los docentes si se tomaran imágenes de clases) (Meo 2010).
} 
nik 2001) identificamos sólo dos artículos por publicación que incluyeran materiales visuales. Estos artículos ofrecen ilustraciones del uso de fotografías, audiovisuales, películas y dibujos en investigaciones sociales ${ }^{10}$. Sólo un trabajo analiza una investigación que utiliza la entrevista de foto-elucidación como principal técnica de producción de datos (Pérez y Torricella 2005) ${ }^{11}$. En cuanto a los eventos especializados, podemos mencionar las Jornadas anuales de Fotografía y Sociedad organizadas por la Facultad de Ciencias Sociales (Universidad de Buenos Aires) desde hace una década; y la realización del Congreso de la International Visual Sociology Association en Buenos Aires en el 2008 ${ }^{12}$. Otro ejemplo del crecimiento paulatino del uso de materiales visuales en sociología es la presentación de ponencias a congresos o jornadas sociológicos. Por ejemplo, en el congreso de sociología celebrado en La Plata a fines de 2008, siete ponencias -de las 125 presentadas- incluyen referencias al uso de material visual de algún tipo (sean películas, fotografías, dibujos). En la mayoría de los casos, se trata de fotografías usadas como medio de registro documental (sacando provecho de la infatigable captación de escenarios y eventos en detalle que logra una cámara).

En este contexto de reciente pero escaso uso de los métodos visuales en sociología, es que desarrollamos nuestra investigación en la Ciudad de Buenos Aires, que se inició en el 2006 y finalizó a mediados del $2010^{13}$. El objetivo gene-

${ }^{10}$ Oubiña (2002) analiza dos películas argentinas de la década del '90 como expresiones críticas del deterioro social y el «mapa arrasado de la Argentina menemista» (195). Aquí son los materiales fílmicos los objetos de análisis, sus argumentos, lógicas internas, y sus referencias sutiles pero patentes al contexto socio-económico y político en el que se inscriben sus historias y personajes. Vernik (2001), por su parte, presenta un audiovisual a cuatro grupos de personas (a los cuales llama «comunidades de apropiación») de diverso nivel socio-económico con el propósito de indagar la recepción del discurso político televisivo. El audiovisual de 7 minutos incluía fragmentos de discurso electoral televisivo, el cual disparaba comentarios espontáneos por parte de los asistentes así como era objeto de reflexión por parte de los asistentes, a partir del llenado de un cuestionario producido para tal fin. Finalmente, el artículo de Monchietti y Sánchez (2008) examina las representaciones sociales de niños y púberes en torno a la vejez a partir de entrevistas y del análisis de los dibujos que éstos crearon sobre el tema y a pedido de las investigadoras.

${ }^{11}$ Este estudio utiliza relatos orales, fotografías familiares y registros arquitectónicos para indagar qué elementos del modelo de familia moderna -configurada en el período 1880-1940- emergen en la estructura de la memoria familiar de una anciana residente en Mar del Plata. as fotografias familiares son utilizadas tanto como disparadores de recuerdos, emociones y perspectivas sobre su historia personal y familiar así como información con peso propio que ofrece líneas de análisis complementarias pero también disonantes respecto de sus relatos orales.

${ }^{12}$ Hasta el momento se han realizado 6 jornadas; a modo de ejemplo, en el último encuentro se problematizaron, entre otros temas, la relación entre fotografía y política, fotografía y memoria, políticas públicas hacia la fotografía, experiencias de trabajos colaborativos de formación o producción con sectores excluidos, fotografía documental e historia social.

${ }^{13}$ La investigación «Nivel medio: culturas institucionales e identidades sociales de jóvenes en situación de pobreza», se desarrolla con subsidio de la Universidad de Buenos Aires (S836) en el Instituto de Investigaciones «Gino Germani» de la Facultad de Ciencias Sociales de la Universidad de Buenos Aires. El equipo de investigación estaba conformado además por Patricia Salti y Soledad Vázquez, quienes participaron en el trabajo de campo junto con las autoras. Todas las investigadoras de este estudio tuvieron dedicación parcial al mismo.

EMPIRIA. Revista de Metodología de Ciencias Sociales. N. ${ }^{\circ} 22$, julio-diciembre, 2011, pp. 13-42. ISSN: 1139-5737 
ral del estudio era conocer los significados atribuidos a la escolaridad media por un grupo de estudiantes en situación de vulnerabilidad social en dos escuelas secundarias estatales del sur de la Ciudad de Buenos Aires; así como indagar sobre su articulación con la producción y reproducción de identidades sociales. Entre estas últimas, se exploraron los modos en que los/as alumnos/as escuelas se autopercibían, entre otros aspectos, como estudiantes, como jóvenes, como varones y mujeres, y, en ocasiones, como madres o padres. Las dos escuelas elegidas se distinguen por su reputación y orientación educativa más o menos inclusiva, siendo la escuela de menor reputación la más proclive a la retención y reinserción educativa de los jóvenes del barrio ${ }^{14}$.

Como parte de nuestra estrategia metodológica, realizamos entrevistas individuales de foto-elucidación (EFE) a una muestra intencional de estudiantes de tercer año, quienes tomaron fotografías de su vida cotidiana adentro y fuera de sus escuelas ${ }^{15}$. Los estudiantes se eligieron considerando el lugar de residencia, el sexo y la edad, teniendo presente su voluntad de participación previamente expresada en una encuesta realizada a los fines de conocer la población escolar de cada institución ${ }^{16}$.

La decisión de realizar EFE fue guiada por el supuesto de que permitiría una comprensión más acabada y rica de las experiencias escolares y de las identidades sociales de los estudiantes ${ }^{17}$ que las entrevistas tradicionales. Siguiendo a la literatura anglosajona que tomamos como punto de partida, supusimos que la EFE promovería: i) un buen intercambio entre nosotras y los sujetos investigados en el corto tiempo disponible, debido a la familiaridad con que los jóvenes las producen, utilizan y circulan ${ }^{18}$; ii) un mayor involucramiento en la investigación; iii) un rol más activo por parte de los jóvenes, donde tuvieran un mayor control de la situación de entrevista y de lo que se discute en ella (Harper 2002, Hazel 1995); iv) una mejor aproximación a las perspectivas y puntos de vista de los jó-

${ }^{14}$ Las instituciones eran conocidas por las investigadoras de estudios anteriores. De todos modos, para validar la elección se hizo una entrevista al supervisor (inspector) de la región que incluía a ambas escuelas, quien coincidió en las diferencias de enfoque institucional ya señaladas.

${ }^{15}$ Antes de las EFE, se aplicaron encuestas a estudiantes de $3^{\circ}$ año de estudio para conocer el perfil sociodemográfico del alumnado. Los datos de estas encuestas fueron utilizados para seleccionar a los estudiantes que tomaron las fotografías y fueron posteriormente entrevistados. En cada escuela se eligieron 8 alumnos de $3^{\circ}$ año de diferente sexo, trayectoria educativa y barrio de residencia. Más allá de la foto-elucidación, se realizaron entrevistas en profundidad a docentes, directivos y preceptores de las escuelas y a uno de los supervisores de la región a la que pertenecían las dos escuelas.

${ }^{16}$ Se priorizó la selección de estudiantes que residieran en una villa de emergencia muy próxima a una de las dos instituciones y a menos de 20 cuadras de la otra. En ésta última participaron además algunos alumnos de otros barrios de la misma zona, lo cual reflejaba su composición socioespacial. Por su parte, la edad permitió distinguir a aquéllos que cursaban tercer año en la edad teórica o esperada de aquellos estudiantes que tenían sobre-edad.

${ }^{17}$ Fischman (2001) propicia su uso para trabajar las identidades juveniles.

${ }^{18}$ Cada vez más los jóvenes naturalizan formas de expresión a través de imágenes más que de enunciados, no sólo en la forma que se presentan al mundo sino también en la forma en que se intenta llegar a ellos como consumidores a través de imágenes visuales (Reguillo Cruz 2000).

EMPIRIA. Revista de Metodología de Ciencias Sociales. N. ${ }^{\circ}$ 22, julio-diciembre, 2011, pp. 13-42. ISSN: $1139-5737$ 
venes sobre la escuela expresados en distintos lenguajes (visuales y orales), y a sus condiciones de vida y mundos sociales, muchas veces inaccesibles para las investigadoras; $y$, finalmente, $v$ ) el acceso a categorías que podríamos no haber contemplado durante la preparación del estudio (Prosser y Schwartz 1998; Harper 2002; Banks 2001).

A continuación, presentamos las decisiones metodológicas, desafíos éticos, las ventajas y desventajas que el uso de la EFE implicó en nuestra investigación. Para ello, organizamos el análisis en tres sub-secciones: antes, durante y después del trabajo de campo. Esta organización temporal nos permitirá captar la complejidad y carácter dinámico del uso de la EFE así como los retos con los que nos enfrentamos en cada instancia. Pese a que, en ciertos aspectos, las fronteras entre estas tres etapas resultan borrosas y la división temporal no sea tan tajante en la práctica de investigación cualitativa -inherentemente flexible en su diseño (Maxwell, 1996)-, se la considera fructífera a los fines de desmenuzar el proceso de investigación en distintos momentos analíticos que permitan al/la lector/a rastrear cómo se llevó a cabo una investigación sociológica que utilizó EFE.

\subsection{Antes del trabajo de campo}

Como en cualquier investigación, en momentos previos al trabajo de campo se negoció el acceso inicial a las escuelas (Hammersley y Atkinson 1994).

Para ello, solicitamos permiso para realizar el estudio a la Secretaría de Investigación (ahora, Ministerio de Educación de la ciudad de Buenos Aires), presentando el proyecto de investigación (sus objetivos y metodología) y los principios éticos que iban a regir nuestros intercambios con adultos y jóvenes en las escuelas ${ }^{19}$. Luego de varios meses, se nos informó que podíamos iniciar nuestra investigación. En ese momento tomamos contacto con las autoridades de las escuelas para presentarles el proyecto y solicitar y negociar el acceso a las instituciones. Las autoridades de las escuelas expresaron su voluntad de participar y colaboraron con la investigación desde el inicio.

Antes del trabajo de campo, también tuvimos que desplegar estrategias para obtener el consentimiento informado de los estudiantes, garantizar la confidencialidad de nuestros encuentros, y obtener el permiso para usar las fotografías que produjeran en el marco de nuestra investigación. Con el propósito de solicitar consentimiento a los adolescentes para participar en el estudio elaboramos: i) un modelo de carta dirigida a los padres o tutores en donde pedíamos su permiso para que los estudiantes participaran, y ii) una guía de los temas que pre-

\footnotetext{
${ }^{19}$ En el sitio del Gobierno de la Ciudad de Buenos Aires puede consultarse la resolución de solicitud de autorización para la realización de trabajos de campo e investigaciones que debe presentarse ante la Dirección de Investigación y Estadísticas para su aprobación como requisito de ingreso a escuelas estatales de la ciudad (http://estatico.buenosaires.gov.ar/areas/educacion/ dirinv/pdf/resoluciontrabajosdecampoeinvestigacionsed.pdf).
} 
sentaríamos a los estudiantes en nuestro primer encuentro (la cual incluía los objetivos del estudio y una mención a nuestro compromiso de respetar la confidencialidad de sus dichos en la escuela y de garantizar el anonimato de la escuela y de sus integrantes por medio del uso de seudónimos).

Asimismo, tuvimos que anticipar y desplegar una estrategia específica para resolver la tensión entre la confidencialidad y el anonimato de los/as entrevistados/as, y el consentimiento de los mismos para el uso de sus fotografías por parte de las investigadoras ${ }^{20}$. Como vimos en la sección anterior, códigos éticos de asociaciones de investigadores sociales y educativos inglesas y argentinas presentan el respeto a la confidencialidad y al anonimato de las personas e instituciones involucradas como horizontes ideales al cual todo estudio debe aspirar. En nuestra investigación, para superar la tensión entre estos principios y la publicación de imágenes producidas por los/as entrevistados/as, se solicitó autorización explícita para el uso de las imágenes y se explicó claramente dónde y con qué propósitos se publicarían. Con esta finalidad, elaboramos un formulario escrito ${ }^{21} \mathrm{o}$ «contrato» (ver Anexo 1). Este «contrato» incluía, en primer lugar, una consigna general que convocaba a los jóvenes a relatar con imágenes cómo era su vida dentro y fuera de la escuela. A continuación, explicitaba nuestras expectativas respecto de su trabajo (los tiempos acordados para la toma fotográfica), nuestras obligaciones (proveerles los equipos, pagar los revelados de las fotos y darles las copias y los negativos en el siguiente encuentro) y sus derechos de propiedad respecto del material fotográfico que produjeran. La última parte de este formulario habilitaba, restringía o prohibía distintos tipos de formas de uso de las fotografías para diferentes audiencias y ámbitos de difusión

En esta primera etapa de la investigación, nos dimos cuenta que la organización de las entrevistas de foto-elucidación demandaba más tiempo que la de las entrevistas tradicionales. Desde un punto de vista práctico, antes del campo, tuvimos que comprar los equipos fotográficos, familiarizarnos con su uso, y elaborar una breve guía técnica para los estudiantes que explicaba cómo utilizar las cámaras descartables. Asimismo, la preparación de la guía de entrevistas fue más complicada de lo anticipado. El equipo de investigación estaba conformado por entrevistadoras con distintas experiencias, formaciones y edades. Sólo dos de las investigadoras contaba con experiencia previa en la realización de EFE. La guía de entrevistas incluyó no sólo la lista de áreas temáticas a explorar sino indicaciones generales de cómo conducir la entrevista. Entre ellas: numerar las fotografías antes de la entrevista; la necesidad de mencionar el número de las fotos durante la entrevista para que quedara registrada en las grabaciones; y la debida atención a indagar las condiciones en las que las fotos se produjeron, las razones de la inclusión o exclusión de ciertas imágenes, y las vinculaciones de los estu-

\footnotetext{
${ }^{20}$ En el contexto argentino, la preocupación por las consideraciones éticas es bastante reciente (para un análisis de este tema, ver Meo 2010).

${ }^{21}$ Este «contrato» fue inicialmente elaborado por Meo (2007) en su investigación de doctorado. En nuestra investigación, realizamos algunas modificaciones a este formulario.
}

EMPIRIA. Revista de Metodología de Ciencias Sociales. N. ${ }^{\circ} 22$, julio-diciembre, 2011, pp. 13-42. ISSN: $1139-5737$ 
diantes con personas y escenarios fotografiados. En suma, tuvimos que dedicarle más tiempo al entrenamiento de las entrevistadoras del equipo que el que hubiéramos utilizado para entrevistas tradicionales. La mayor complejidad de la guía exigió un tiempo extra de capacitación en los aspectos específicos de las EFE.

Un desafío central de esta fase de la investigación fue elaborar un instrumento que lograra un buen guión de entrevista -a sabiendas que siempre la secuencia es «teórica» y que se renegociará en cada encuentro- aún sabiendo que a la incertidumbre propia de una entrevista en profundidad convencional se agregaba, en este caso, la incertidumbre sobre los temas elegidos y las secuencias de las fotografías tomadas por los estudiantes.

\subsection{Durante el trabajo de campo}

Después que las instituciones aceptaron participar en el estudio iniciamos el trabajo de campo a fines de marzo de 2007 con la realización de reuniones con grupos de jóvenes de tercer año de ambas escuelas. Los estudiantes habían sido elegidos a partir de los resultados de la encuesta que indagaba su voluntad de participar en esta fase de la investigación. Todos los estudiantes convocados aceptaron participar, mostrándose interesados y entusiasmados.

En un primer encuentro describimos el proyecto de investigación, e invitamos a los estudiantes a tomar fotografías de sus vidas dentro y fuera de la escuela, y a encontrarse con nosotras para hablar de sus imágenes ${ }^{22}$. Utilizando el «contrato» elaborado con anterioridad, acordamos las fechas para la realización de la toma fotográfica ${ }^{23}$. En esta oportunidad, les entregamos las solicitudes de autorización que debían traer firmadas por sus padres o tutores antes de iniciar su participación en la foto-experiencia. También distribuimos cámaras descartables con rollos de 24 fotos y acordamos que en siete días volveríamos a visitarlos para retirar los equipos y convenir horarios para encontrarlos, darles las fotografías y conversar sobre ellas. En la segunda reunión, luego de ver las imágenes, explicamos la segunda parte del «contrato» que diseñamos para obtener consentimiento de los jóvenes a utilizar sus imágenes en distintos medios y publicaciones (tales como conferencias, artículos especializados, etc.) (ver segunda parte del contrato en Anexo 1).

El uso del «contrato» nos permitió dialogar con los estudiantes sobre los posibles usos de sus imágenes, así como dejarles en claro que ellos tenían propiedad sobre sus fotos y control sobre el uso posterior de las mismas. En la mayoría de los casos, los jóvenes nos autorizaron a utilizar muchas de las fotografías en diversas publicaciones académicas y especializadas. Tanto este «contrato»

\footnotetext{
${ }^{22}$ En esta época también solicitamos autorización a los directivos para que pudieran tomar fotografías en sus escuelas.

${ }^{23}$ En este encuentro utilizamos la primera parte del «contrato» (Ver Anexo 1).
} 
como los pedidos de autorizaciones a padres y autoridades escolares fueron dispositivos centrales para dar respuesta a los desafíos éticos que -como toda investigación que utiliza EFE- debíamos sortear. En el caso de los «contratos», consideramos que fue útil tanto para solicitar el consentimiento de los estudiantes, como para brindarles la oportunidad de reflexionar sobre los posibles usos de sus fotos así como de negarse a su publicación (Pink 2006).

Durante esta etapa de trabajo de campo, el uso de las EFE supuso numerosas ventajas y desventajas. Entre las primeras, al igual que muestran otros estudios internacionales (Bolton et al. 2001; Hazel 1995; Holliday 2000), el uso de fotos producidas por los/as entrevistados favoreció notablemente el entendimiento mutuo con las investigadoras. En principio, los estudiantes asumieron la tarea con entusiasmo. Al momento de entregarles sus fotografías, en la mayoría de los casos estaban impacientes por ver sus imágenes y muy predispuestos a vernos y encontrarnos. Durante la entrevista, el «mostrar fotos» promovió rápidamente una cercanía y familiaridad entre los/as estudiantes y las investigadoras que hubiera sido casi imposible recrear en una entrevista tradicional. El ritual de «mostrar sus fotos» permitió generar una situación de intercambio cómoda, en la que la risa, las sorpresas y las emociones estaban siempre presentes. Los jóvenes disfrutaron así de la visualización de sus fotografías, y su entusiasmo y curiosidad para ver los resultados de su toma fotográfica facilitaron que nos hablaran de sus familias, hogares, escolaridad y deseos ${ }^{24}$.

Otra ventaja del uso de las EFE es que las y los estudiantes pudieron poner en imágenes sus puntos de vista sobre su mundo social de una manera vívida y cargada de emociones (Becker 2002, Wang, et. al. 1996; Harper 2002). Así, los estudiantes documentaron con sus imágenes tanto formas de exclusión, marginación y vulnerabilidad como diferentes formas de resistencia (individuales, familiares, grupos de amigos y políticas). Por ejemplo, Claribel ${ }^{25}$ tomó fotografías de la villa, de su casa, familia y de lo que comen (ver Imagen 1). En sus descripciones de las imágenes (ver Relato 1), Claribel denunció las privaciones materiales de su familia, las profundas desigualdades entre grupos sociales y el carácter político de las mismas.

${ }^{24}$ La única excepción fue la de un estudiante varón cuya familia estaba atravesando un momento crítico para garantizar su supervivencia básica y que se mostró sumamente triste y desganado al tomar sus fotografías y al comentarlas con las investigadoras.

${ }^{25}$ Todos los nombres de personas e instituciones son seudónimos. En el caso de los jóvenes, los nombres fueron elegidos por las y los entrevistados.

EMPIRIA. Revista de Metodología de Ciencias Sociales. N. ${ }^{\circ} 22$, julio-diciembre, 2011, pp. 13-42. ISSN: $1139-5737$ 
Imagen 1. La villa según Claribel: el rancho de su tía discapacitada

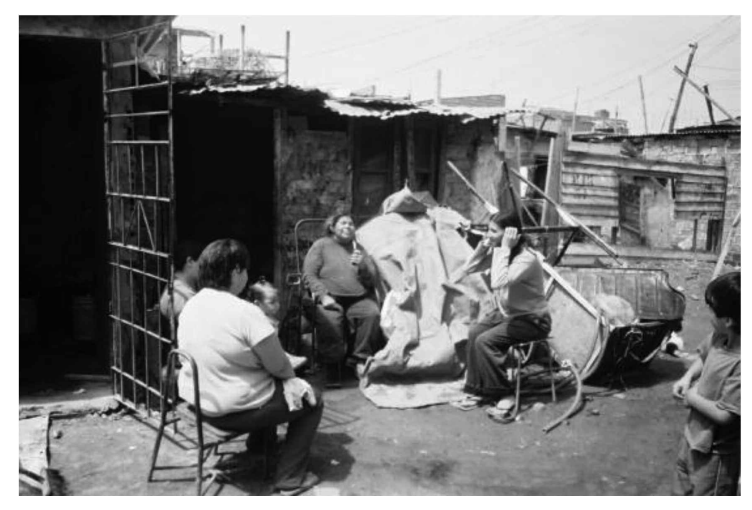

Relato 1: Claribel: de la villa quería mostrar las casitas y mostrarte mi casa de afuera.

Entrevistadora: y cómo es tu casa de afuera?

Claribel: mi casa de afuera tiene tres cartones y una chapa, así de since$\mathrm{ra}$, tres cartones y una chapa, y mostrarte las personas que viven dentro de la villa porque por acá hay una fotografía que mi tía es discapacitada, ella no recibe ningún plan, no recibe nada y tiene que estar así como la ves inválida, sin una pierna, ella tiene que ir a cirujear para poder mantenerse, y yo quería mostrar eso, quería mostrarles cómo se vive adentro de la villa, nada más.

La Imagen 1 (al igual que la mayoría de las fotografías) también registra la importancia de los afectos, las familias y los amigos. En esa imagen, por ejemplo, el mate, las sonrisas, y la charla testimonian la importancia de las redes de sociabilidad y reciprocidad para resistir a las injusticias, la marginación, la ignorancia y condena social de los «otros», y la indiferencia del Estado (Murmis y Feldman 2002). Las estrategias de vida de la mayoría de los/as estudiantes y sus familias aparecían en las imágenes y relatos como engarzadas a las vidas de otros y otras (familiares, vecinos, amigos). La densidad de esas redes variaba de estudiante a estudiante y aparecía asociada a sus niveles de integración social o vulnerabilidad.

La EFE también permitió que los entrevistados tuvieran mayor control sobre la situación de entrevista. Las conversaciones giraron en torno a sus imágenes y nuestras preguntas trataron de indagar los sentidos atribuidos a los lugares, actores y acciones registrados, las condiciones en las que se tomaron las imágenes, y las motivaciones de los estudiantes para tomarlas. Si bien las entrevistadoras tenían una agenda de temas a explorar, las fotografías fueron el punto de partida y objeto central de las entrevistas.

Finalmente, una ventaja inesperada del uso de los «contratos» para solicitar el consentimiento de los estudiantes fue que nos facilitaron el acceso y permanencia en las escuelas: las autoridades escolares y los docentes valoraron la 
importancia que le otorgamos a los deseos de los estudiantes. Asimismo, las autoridades de la escuela consideraban que participar en la investigación podría ser una experiencia constructiva e interesante para los estudiantes.

Durante el trabajo de campo, la realización de este tipo de entrevistas también supuso desventajas y escollos de distinto tipo. En primer lugar, el más serio de los problemas fue que dos estudiantes varones de una de las escuelas fueron robados a las pocas horas que les entregamos las cámaras ${ }^{26}$. Si bien los hechos de este tipo son comunes (según los relatos de los estudiantes), estos sucesos nos llevaron preguntarnos si haberles dado las cámaras no generó una situación de mayor vulnerabilidad y riesgo. En la literatura internacional consultada hace escasa mención a este tipo de situaciones, con la excepción de la investigación de Joanou (2008) en Lima que también trabajó con jóvenes (en su caso, en situación de calle) y de Karlsson (2001) que realizó EFE con estudiantes sudafricanos. Estas experiencias ponen de relieve los recaudos éticos que los/as investigadores/as deben intentar anticipar para preservar a sus informantes.

Otra de las desventajas de las EFE fue la dificultad de las investigadoras para «manejar» la situación de entrevista. En las entrevistas tradicionales, la persona que entrevista tiene una agenda de temas que le interesa indagar. En las EFE, las fotos operan como disparadores de los relatos de los/as estudiantes y de las preguntas de las investigadoras. Así, en la EFE los/as entrevistadores/as deben ser capaces de indagar no sólo la línea teórica y temática que les interesa sino también la línea argumental de los relatos y de las imágenes producidas por los/as entrevistados (Bourdieu 2007). En este sentido, las EFE fueron difíciles de realizar y, en muchos casos, las investigadoras no lograron indagar con profundidad todos los temas que estaban en su «agenda» de investigación. En ocasiones, el seguimiento detallado de las fotografías nos tendió una «trampa descriptiva», donde los fotógrafos tomaron la palabra para relatar extensamente las fotos y donde quienes entrevistaron perdieron la oportunidad de ir conectando esa descripción con las preguntas significativas en el estudio (esto no significa obturar la posibilidad de dejar emerger nuevos temas sino que alude a la falta de flexibilidad para conducir la entrevista por parte del entrevistador). En otras entrevistas, la gran diversidad de escenarios, personajes y temáticas de las fotografías complicó la conducción de la entrevista. Cuando quienes entrevistaron no tenían experiencia en realizar EFE, fue muy difícil para ellas desentrañar temas relevantes y emergentes a partir - pero también más allá- de las fotografías. En algunas entrevistas, en cambio, sucedió lo contrario: los entrevistados no dijeron demasiado de las fotografías asumiendo que «las imágenes hablan por sí mismas» (Meo 2008).

Otra dificultad adicional que enfrentamos al realizar EFEs fue que, en ocasiones, la ausencia de imágenes relativas a temas de nuestro interés tornó más compleja la tarea de hacer preguntas sobre aquellos (tal es el caso de la falta de

\footnotetext{
${ }^{26}$ Los equipos eran descartables y de bajo costo.
} 
fotografías escolares entre muchos de ellos, cuando la perspectiva sobre la escuela resultaba un tema central del estudio).

En cuanto a los escollos de carácter técnico, surgieron dos inconvenientes: la baja calidad de varias fotografías y la falla de los equipos y los rollos fotográficos (dos estudiantes nos avisaron que las cámaras no funcionaron y un rollo de fotos salió velado). En este último caso, debimos volver a las escuelas a reponer los equipos, lo cual generó retrasos en el trabajo de campo, viajes no planeados a las escuelas y mayores costos económicos. La baja calidad de las fotografías, en cambio, resultó de las propias limitaciones de las cámaras tanto como de errores fotográficos, aspectos que podrían mejorarse en futuras experiencias de investigación.

Como elementos contextuales que dificultaron el trabajo también cabe agregar la suspensión de clases por problemas de infraestructura en las escuelas, falta de espacios con cierta privacidad para realizar las entrevistas y tiempos suficientes para realizarlas, etc. También hubo variables niveles de compromiso por parte de los estudiantes: hubo demoras en el trabajo pautado; en casos puntuales, se evidenció un interés centrado en las fotografías y mucho menos en los encuentros posteriores; así como también hubo dificultades para concertar reencuentros con alumnos cuando faltaban a las citas para entregar sus cámaras o para ser entrevistado.

\subsection{Después del trabajo de campo}

Una vez finalizado el trabajo de campo, nos dispusimos a organizar y sistematizar ${ }^{27}$ los materiales recolectados y producidos con el propósito de poder manejarlos y analizarlos. Miles y Huberman definen el «manejo de los datos» como «las operaciones necesarias para desarrollar un proceso coherente y sistemático de recolección, almacenamiento y recuperación de datos» (1994: 254). Estas operaciones buscan asegurar la accesibilidad de los datos y de los análisis realizados, la calidad de los materiales recolectados y su preservación una vez finalizada la investigación. Durante el trabajo de campo, recolectamos gran cantidad de materiales de distinto tipo: cassettes con las entrevistas, notas de campo con los registros observacionales durante nuestra estadía en las escuelas, documentos institucionales, y fotografías.

Los materiales recabados debieron ser editados y procesados antes de poder ser analizados. Por ejemplo, las entrevistas fueron transcriptas con cuidado y fueron completadas con información contextual sobre la situación de entrevista. Luego se utilizó un software de análisis cualitativo en el que volcamos las notas

${ }^{27}$ Este proceso se inició en el trabajo de campo, sin embargo, la organización de todas las entrevistas y material fotográficos se dio al final de trabajo de campo. Una vez que todas las entrevistadoras concluyeron con sus respectivas entrevistas y que éstas fueron transcriptas por una persona contratada para tal fin.

EMPIRIA. Revista de Metodología de Ciencias Sociales. N. ${ }^{22}$, julio-diciembre, 2011, pp. 13-42. ISSN: $1139-5737$ 
como las transcripciones. En el caso de las fotografías, entre otros procedimientos de sistematización, se procedió a generar archivos únicos por estudiante en procesadores de textos.

Imagen 2. Panorámica de la villa, tomada por Martín

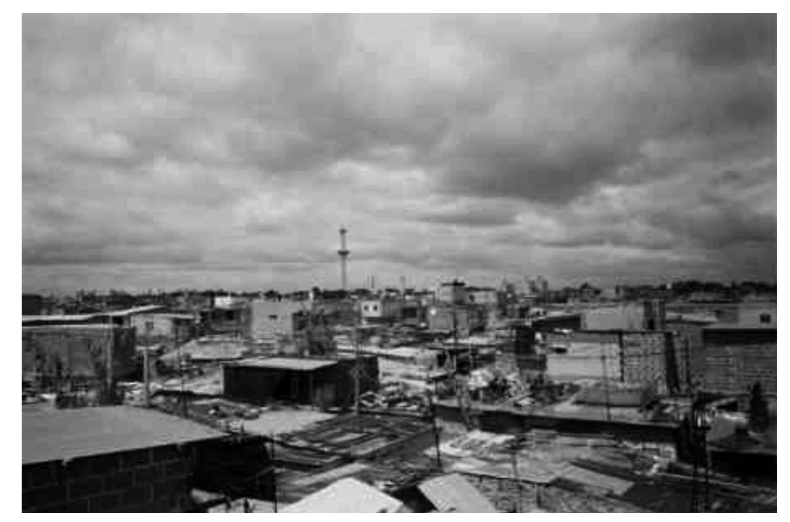

Relato 2: «yo lo que veo acá en la villa son muchas cosas malas...afuera de la villa no sé...como yo convivo ahí adentro... mucho robo, ahora también se ve mucho secuestro, es lo que se está viviendo ahora» (Martín).

Imagen 3. La otra cara de su barrio

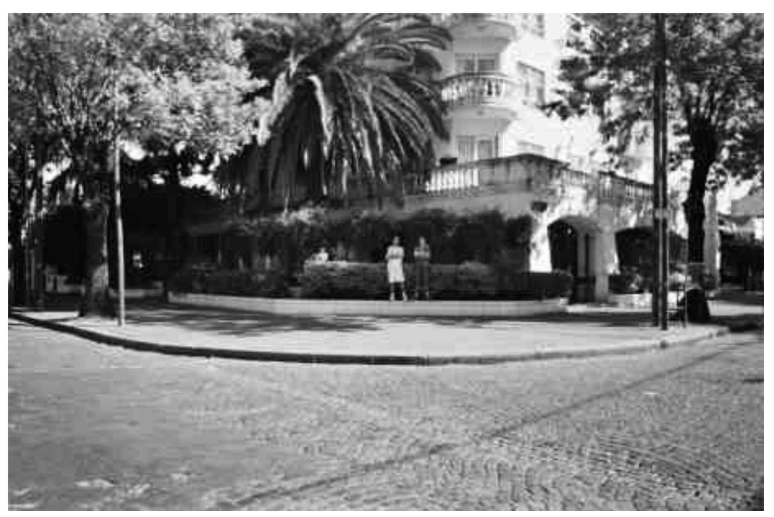

Relato 3: «Saqué porque son lugares lindos, fuimos a caminar y pasamos por unas casas que están lindas» (Martín). 
Respecto de los desafíos éticos posteriores al trabajo de campo, también pusimos a nuestra propia consideración si había en los álbumes de los estudiantes fotografías que, a nuestro entender y más allá de la autorización firmada anteriormente por ellos, pudieran comprometerlos con los adultos, con sus pares o familiares. Pink (2007) señala que la existencia de un consentimiento firmado no implica que los investigadores tengan derecho a usar las imágenes de modos ilimitados, puesto que deben definir responsable y cuidadosamente qué fotografías pueden dañar o poner en riesgo a sus informantes.

En cuanto a las ventajas de las EFE tras el trabajo de campo, las imágenes y los relatos nos condujeron a problematizar -en el momento del análisis- aspectos que no consideramos relevantes antes del trabajo de campo (Bolton, et al. 2001; Hazel 1995; Holliday 2000). Por ejemplo, la importancia del barrio como principal marco de acción de sus intercambios sociales cotidianos (Merklen 2005). Muchas fotos y relatos registraban un fuerte contrapunto entre el «adentro» y el «afuera» de la villa, las cuales nos llevaron a consultar material sobre los debates en torno a los procesos de territorialización (ver abajo Imágenes 2 y 3 y Relatos 2 y 3). En el caso de los jóvenes en situación de pobreza, algunos autores señalan que la territorialización tiene efectos en la constitución de las identidades y experiencias juveniles, anclándolos en términos sociales y culturales al territorio socio-espacial inmediato que habitan (Duschatzky 1999; Feijoó 2001; Reguillo Cruz 2000). En el caso de varios de los/as jóvenes de nuestro estudio, las imágenes de la villa y de sus vidas en ella eran muy frecuentes. En algunos casos, los jóvenes también fotografiaban un «afuera» al que visitaban esporádicamente. Este «afuera» era cercano geográficamente (por ejemplo, la plaza del barrio, la estación de trenes, etc.) pero distante socialmente. Por ejemplo, Martín tomó fotografías panorámicas de la villa y también del «afuera». Las imágenes y los relatos subrayan las diferencias (arquitectónicas, estéticas, morales, culturales y sociales) entre estos territorios.

Otra ventaja de la EFE es la posibilidad que ofrece de integrar distintas perspectivas en el análisis, en comparación con la evidencia textual: la composición de las imágenes, la mirada de su/s autor/es y la del espectador, audiencia u observador (Rose 2006, Augustowsky et. al. 2008). En esta investigación coincide el productor y el espectador de las imágenes: cada uno de los alumnos que participaron en la toma fotográfica. Mientras en algunos análisis trabajamos separadamente aspectos relativos a la composición de las imágenes (Dabenigno et. al. 2005), en otros integramos fotografías y relatos de entrevista (Dabenigno y Salti 2006; Dabenigno et. al. 2008).

Las principales dificultades de este estudio con EFE después del trabajo de campo fueron de carácter técnico y analítico. En primer lugar, el hecho de haber usado dos tipos de programas para almacenar entrevistas y fotografías supuso dificultades para su posterior manejo, vinculación, codificación y análisis. La cantidad de material fotográfico (alrededor de 400 fotografías) producido tornó aún más complejo su manejo. En ese momento, no contábamos con conocimientos acerca de las posibilidades de usar un único software que manejara imá- 
genes y textos de entrevista. En segundo término, fue muy difícil sistematizar y analizar un corpus que combinara palabras e imágenes. Al inicio de la investigación no se contaba con un modelo de análisis de las imágenes a seguir y el tipo de análisis elegido combinó algunas técnicas de análisis cualitativo tradicional con algunas herramientas utilizadas por otras investigaciones con imágenes (Banks 2001; Jewitt 1997). Entre ellas, vale la pena mencionar: construcción de matrices (para clasificar sintéticamente las principales categorías emergentes de entrevistas y fotografías $)^{28}$, codificación de entrevistas en software de análisis cualitativo, armado de álbumes fotográficos para cada caso, creación de archivos temáticos con integración de relatos y fotografías para cada entrevistado/a, y análisis del contenido de las fotos desde una perspectiva cuantitativa. Por ejemplo, para explorar los significados sobre la escuela emergentes de fotos escolares y de los relatos de entrevistas comenzamos con una mirada general que contabilizaba las imágenes cuyo escenario era la escuela, identificando las tomadas en el aula y en los demás espacios escolares. Luego, armamos el álbum de fotografías escolares de cada estudiante para realizar un análisis de su contenido temático. Como tercer paso, utilizamos los segmentos de entrevista vinculados a la escuela, resultantes de la codificación de las EFE en un software de análisis cualitativo. Por último, integramos los segmentos de entrevista a los álbumes de fotografías (realizados en un procesador de textos) que correspondían a comentarios de los estudiantes sobre cada una de las imágenes escolares.

En resumen, la poca experiencia en el trabajo de codificación y análisis de imágenes, sumada a la escasez de materiales bibliográficos que sistematizaran procedimientos y perspectivas de análisis de datos provenientes de EFE condujo a ensayar diferentes formas de tratamiento y análisis de estas evidencias.

El análisis de los textos escritos y las imágenes se plasmó en diferentes textos (ponencias, artículos y capítulos de un libro en prensa) los cuales han examinado sus complementariedades, encuentros y desencuentros con el propósito de desentrañar el sentido atribuido a la escolaridad en el nivel medio (por ejemplo, Dabeningo, Meo y Vázquez 2008; Dabeningo y Salti 2006; Meo y Dabeningo 2010). El análisis -entre otras cosas- mostró la valoración positiva de la escuela media por parte de jóvenes de sectores populares. Ellos la interpretan como un espacio en donde se sienten «bien», «respetados» y «acompañados». En otras palabras, los estudiantes la ven como un lugar que los acepta con sus particularidades, en donde ellos aspiran a aprender conocimientos y a forjar herramientas para un futuro mejor. Asimismo, la ven como un espacio en donde

${ }^{28}$ Las matrices son un modo de sistematizar los datos cualitativos a los fines del análisis (Miles y Huberman 1994). Nuestras matrices asumieron la forma de cuadros de doble entrada en los cuales ubicamos los casos en las filas y las categorías o dimensiones de análisis en las columnas, completando las celdas con palabras clave y algunas breves citas de entrevistas o referencias al número de fotografía al que refería el concepto aludido. Frente a la codificación en sofwares cualitativos tienen la ventaja de una mayor claridad visual y de condensar la información de manera tal que facilita la identificación de patrones y la detección de categorías más y menos ricas en la densidad de los datos.

EMPIRIA. Revista de Metodología de Ciencias Sociales. N. ${ }^{\circ}$ 22, julio-diciembre, 2011, pp. 13-42. ISSN: $1139-5737$ 
se promueven relaciones con pares y adultos basadas en valores como el cuidado y la tolerancia - que muchos veces contradicen las dinámicas de interacción que rigen su vida más allá de la escuela. Asimismo, el análisis de los datos sugiere que se ha producido una expansión de las aspiraciones educativas y ocupacionales de los jóvenes de nuestro estudio respecto de generaciones anteriores (la mayoría de sus padres o adultos en sus familias no terminaron el nivel medio de educación). Sin embargo, también se argumenta que esta ampliación de expectativas no ha sido acompañada por condiciones materiales, sociales e institucionales que contribuyan a su realización futura. Al contrario, la persistencia de condiciones de pobreza material, la obligación de trabajar, la maternidad -en algunos casos- y la falta de mecanismos institucionales que articulen las expectativas con los posibles futuros educativos en el nivel superior minan las posibilidades futuras de estos jóvenes (en distinto grado y combinación en los diferentes casos individuales).

\section{REFLEXIONES FINALES}

Este artículo comenzó revisando las principales potencialidades, limitaciones y desafíos del uso de la EFE identificados por literatura anglosajona consultada. Estas primeras argumentaciones promovieron un uso reflexivo de la EFE que trascendiera el encantamiento de la técnica y discutiera de manera situada su pertinencia en estudios empíricos concretos. Inspiradas en esta idea, la segunda sección evalúa el alcance de la EFE en una investigación propia realizada en la Ciudad de Buenos Aires. Así, esta sección desgrana las decisiones metodológicas, ventajas, dificultades y desafíos éticos en tres momentos de la investigación: el «antes», el «durante», y el «después» del trabajo de campo. El balance de la inclusión de esta técnica de entrevistas ha sido positivo. Más allá de las dificultades encontradas (principalmente durante y después de la realización de las entrevistas), este tipo de diseño nos permitió indagar aspectos vinculados con las identidades sociales, la sociabilidad juvenil y barrial y los sentidos atribuidos a la experiencia escolar que hubieran sido difíciles de abordar en una entrevista tradicional (basada en palabras). Las fotografías no sólo despertaron el interés de los estudiantes y facilitaron el diálogo de las investigadoras con los/as jóvenes sino que también enriquecieron el acervo de materiales empíricos y los sentidos a ser analizados.

A la vez, este artículo visibilizó el carácter complejo y trabajoso de las investigaciones que incluyen EFE. Sin embargo, si bien las dificultades fueron muchas y diversas, el uso de la EFE operó como un instrumento que vertebró nuestra investigación y que nos posibilitó acceder a los mundos sociales de los adolescentes entrevistados y sorprendernos, dado el poco tiempo y recursos con los que contábamos.

Algunas de las ventajas y desventajas de la EFE identificadas en nuestra investigación fueron similares a las documentadas por bibliografía internacional (el 
rápido entendimiento mutuo y la colaboración de los estudiantes que logramos durante las entrevistas, el acceso a escenarios de su vida diaria poco accesibles para nosotras o el descubrimiento de nuevas categorías, entre las primeras, y los mayores recursos y esfuerzos que demanda la EFE frente a una entrevista exclusivamente basada en palabras, entre las segundas). Pero también encontramos beneficios y problemas particulares a nuestro contexto de investigación. Entre los primeros, la favorable aceptación de la EFE por parte de los adultos en la escuela. Entre las dificultades específicas, la puesta en riesgo de los estudiantes por el uso de cámaras fotográficas en contextos de alta vulnerabilidad social. Aprendimos numerosas lecciones de esta experiencia. Entre ellas, en contextos como el argentino, es necesario evaluar muy cuidadosamente las posibles consecuencias de distribuir cámaras a jóvenes en situación de vulnerabilidad social. Será necesario tener muy presente y evaluar con autoridades, docentes y jóvenes los riesgos de participar en una foto-experiencia.

Asimismo, es fundamental anticipar los desafíos éticos, prácticos y técnicos que pueden en este tipo de diseños. A su vez, quienes investigan deben sopesar las posibles ventajas y limitaciones del uso de la EFE en sus respectivos estudios. Entre ellas: el mayor tiempo que lleva la organización de este tipo de investigaciones, la mayor capacitación que requieren quienes realizan las entrevistas ante la complejidad de conducir una entrevista guiada por fotografías pero también por los interrogantes de la investigación (a veces próximos y otras más distante a los contenidos de las imágenes) y la mayor complejidad del análisis de materiales visuales. Los recaudos éticos también exigen reflexionar antes, durante y luego del trabajo de campo. La necesidad de instrumentar el tipo de consentimiento informado más conveniente para la población estudiada, los distintos acuerdos para la toma fotográfica que en el caso de trabajar con estudiantes menores de edad requieren el consenso con instituciones, tutores o padres y con los propios participantes, la revisión de las posibilidades reales de contribuir a vulnerabilizar a los estudiantes en posteriores difusiones de sus fotografías, son responsabilidades ineludibles para los investigadores.

Como asunción metodológica básica, concebimos la EFE como una técnica de entrevista disponible -ni más ni menos loable que otros métodos de uso más difundido y aceptado- cuya pertinencia dependerá de los objetivos y recursos materiales y humanos disponibles. En tal sentido, este artículo ha brindado elementos para promover una apropiación reflexiva de la EFE en la investigación sociológica en Argentina e Iberoamérica, con una mirada atenta a no caer en usos acríticos propios de modas metodológicas pasajeras.

\section{BIBLIOGRAFÍA}

Augustowsky, G., Massarini, A., Tabakman, S. (2008): Enseñar a mirar imágenes en la escuela, Buenos Aires, Tinta Fresca.

BANKs, M. (2001): Visual methods in social research, London, SAGE Publications.

EMPIRIA. Revista de Metodología de Ciencias Sociales. N. ${ }^{\circ}$ 22, julio-diciembre, 2011, pp. 13-42. ISSN: 1139-5737 
BECKER, H. (2002): «Visual evidence: A Seventh Man, the specified generalization, y the work of the reader», Visual Studies $17 \mathrm{~N}^{\mathrm{o}} 1$ : 1-11.

Bolton, A., Pole, C. y Mizen, P. (2001): «Picture this: researching child workers», Sociology 35(2): 501-518.

Bourdieu, P. (2007): La miseria del mundo, Buenos Aires, Fondo de Cultura Económica.

British EDUCATIONAL RESEARCH AsSOCIATION (2004): Revised ethical guidelines for educational research. London, British Educational Research Association.

British Sociological AsSOCIATION (2002): Statement of ethical practice for the British Sociological Association. Durham, British Sociological Association.

Campos Monteiro, J. M., \& Dollinger, M. (1998): «An autophotographic study of poverty, collective orientation, and identity among street children», The Journal of Social Phychology, 138(3), 403-406.

DABEnigno, V. y SAlti, P. (2006): «Territorio e identidad en jóvenes escolarizados de sectores populares», 8vo. Congreso de Antropología Social, Salta, Argentina, 19 al 22 de septiembre de 2006.

Dabenigno, V., Meo, A.y Salti, P. (2005): «La Presentación de los Jóvenes como Alumnos», XVI Congreso Mundial de Educadores Sociales, organizado por Asociación Internacional de Educadores Sociales (AIEJI), 15 al 18 de noviembre de 2005, Montevideo, Uruguay.

Dabenigno, V., Meo, A. y VAZQuez, S. (2008): «Masculinidades en foco: relatos visuales y orales de varones jóvenes de sectores populares de la Ciudad de Buenos Aires», IVSA Conference «Space, Time and Image», Buenos Aires, 6 al 8 de Agosto de 2008.

De Miguel, J. (2003): «El ojo sociológico», Revista Española de Investigaciones Sociológicas 101: 49-88, Madrid: Centro de Investigaciones Sociológicas.

De Miguel, J. y Ponce De León, O. (1998): «Para una sociología de la fotografía», Revista Española de Investigaciones Sociológicas 84: 83-124, Madrid: Centro de Investigaciones Sociológicas.

DusChATSKY, S. (comp.) (2000): Tutelados y asistidos. Programas sociales, políticas públicas y subjetividad. Buenos Aires, Paidós.

Epstein, I., Stevens, B., Mckeever, P. And BARuchel, S. (2006): «Photo Elicitation Interview (PEI): Using Photos to Elicit Children's Perspectives», International Journal of Qualitative Methods 5(3). Disponible en: http://www.ualberta.ca/ iiqm/ backissues/5_3/PDF/epstein.pdf (fecha de consulta: 26 de diciembre de 2009).

FeIJoo, M. C. (2001): Nuevo país, nueva pobreza. Buenos Aires, Fondo de cultura Económica.

FISCHMAN, G. (2001): «Reflections about images, visual culture, y educational research.» Educational researcher noviembre: 28-33. Disponible en: http://www.aera.net/pubs/er/pdf/vol30_08/AERA300805.pdf (fecha de consulta: 24 de junio de 2004).

FischMAN, G. (2002): «Cultura visual y educación. Reflexiones sobre la utilización de imágenes en la investigación educativa», Revista electrónica de la Escuela de Posgrado de la UNSAM. Disponible en: http://e-mag.posgrado.unsam.edu.ar/R0304/ fischman.htm (fecha de consulta: 26 de junio de 2004).

GALLMAN, S. (2009): «The truthful messenger: visual methods and representation in qualitative research in education», en Qualitative Research 9: 197-217.

Gates, M. (1976): «Measuring Peasant Attitudes to Modernisation: A Projective Method», Current Anthropology, 17(4), 641-665. 
GoLD, S. (1991): «Ethnic boundaries and ethnic entrepreneurship: a photo-elicitation study», Visual Sociology 6(2): 9-22.

Hammersley, M. y P. AtKinson, (1994): Etnografía. Métodos de investigación, Barcelona, Paidós.

Hareven, T., \& Langenbach, R. (1978): Amoskeag: Life and Work in an American Factory City, New York, Pantheon Press.

HARPER, D. (1998): «Sobre la autoridad de la imagen. El método visual en la encrucijada», en Norman K. Denzin \& Yvonna S. Lincoln (Ed.) Collecting and Interpreting Qualitative Materials, London, SAGE Publications, pp. 130-147.

HARPER, D. (2002): «Talking about pictures: a case for photo elicitation», Visual Studies 17(1): 13-26.

Hazel, N. (1995) «Elicitation techniques with young people», Social research Update(12): http://www.soc.surrey.ac.uk/sru/SRU12.html.

HollidAY, R. (2000): «We've been framed: visualising methodology», The Sociological Review 48(4): 503-521.

HURWORTH, R. (2003): «Photo-Interviewing for research», Social Research Update (40): http://www.soc.surrey.ac.uk/sru/SRU40.html

JewitT, C. (1997): «Images of Men: Male Sexuality in Sexual Health Leaflets and Posters for Young People», Sociological Research Online, vol. 2, no. 2. Disponible en: http://www.socresonline.org.uk/2/2/6.html (fecha de consulta: 2 de Diciembre de 2009).

JOANOU, J. P. (2008): «The good, the bad and the ugly: Ethical concerns in participatory photographic methods with children living and working on the streets of Lima, Peru», IVSA International Conference 2008, FLACSO, Buenos Aires, Argentina.

KAPLAN, I., LEWIS, I. y MUMBA, P. (2007): «Picturing global educational inclusion? Looking and thinking across students» photographs from the UK, Zambia and Indonesia», Journal of Research in Special Educational Needs 7(1): 23-35.

KARLSSON, J. (2001): «Doing Visual Research with School Learners in South Africa», Visual Studies, Volume 16 (2): 23-37.

MaXwell, J. A. (1996). Qualitative research design. An interactive approach, London, Sage Publications.

MCGREGOR, J. (2004): «Space, power and the classroom», Forum, 46(1), 13-18.

MeO, A. (2005): «Lo personal y lo profesional: Algunas reflexiones en torno a la relación investigador- sujetos investigados en un trabajo etnográfico en dos escuelas secundarias de la Ciudad de Buenos Aires». En Palermo, Alicia Itatí y Cappellacci, Inés Coordinadoras: Las relaciones entre la teoría y la metodología en la investigación educativa, ISP J. V.González, Departamento de Educación, Universidad Nacional de Luján.

Meo, A. (2007): «Social Class, Identities y Secondary Schooling: An Ethnographic Study in Two Schools of the City of Buenos Aires», Department of Sociology, Vol. $\mathrm{PhD}$, Coventry: University of Warwick.

Meo, A. (2008): «Taking photographs to make sense of the world? The advantages and limitations of photo-elicitation in a qualitative study in the city of Buenos Aires (Argentina)», IVSA International Conference 2008, FLACSO, Buenos Aires, Argentina.

Meo, A. (2010): «Consentimiento informado, anonimato y confidencialidad en investigación social. La experiencia internacional y el caso de la sociología en Argentina», Aposta $\mathrm{N}^{\circ} 44,1-30$. Disponible en: http://www.apostadigital.com/revistav3/hemeroteca/aines.pdf. (fecha de consulta: 14 de enero de 2010). 
Meo, A., Dabenigno, V., Salti, P. Y RodríGuez, P. (2005): «Algunos aportes del uso de imágenes para el estudio de identidades sociales de jóvenes-adolescentes escolarizados de sectores populares». En Palermo, Alicia Itatí y Cappellacci, Inés Coordinadoras: Las relaciones entre la teoría y la metodología en la investigación educativa, ISP J. V.González, Departamento de Educación, Universidad Nacional de Luján.

Merklen, D. (2005): Pobres ciudadanos. Las clases populares en la era democrática (Argentina, 1983-2003), Buenos Aires, Gorla.

Miles, M. y Huberman, M. (1994): «Data Management and Analysis Methods», en Denzin, N. e Y. Lincoln (eds.), Handbook of Qualitative Research, Thousand Oaks, Sage Pulbications, Cap. 27, pp. 428-444.

Mitchell, C., y Weber, S. (1998): «Picture this! Class line-ups, vernacular portraits and lasting impressions of school», en J. Prosser (Ed.), Image-based research. A sourcebook for qualitative researchers (pp. 197-213). London, Falmer Press. Taylor \& Francis Group.

Mizen, P. y Ofosu-Kusi, Y. (2007): «Researching with, not on: using photography in researching street children in Accra, Ghana», en Studies in Qualitative Methodology, Volume 8, 57-81.

Monchietti, A. y SÁnchez, M. (2008): «Acerca de la génesis de la representación social de la vejez», Revista Argentina de Sociología, 6: 143-150.

Murmis, M. y Feldman, S. (2002): «Formas de sociabilidad y lazos sociales», en Sociedad y sociabilidad en la argentina de los 90, Buenos Aires, Universidad Nacional de General Sarmiento - Editorial Biblos.

Noland, C. M. (2006): Auto-Photography as Research Practice: Identity and Self-Esteem Research, Journal of Research Practice 2(1): M1.

OubiÑA, D. (2002): «Un mapa arrasado. Nuevo cine argentino de los «90», Sociedad $\mathrm{N}^{\circ}$ 10: $193-205$.

Pérez, I. Y. ToRricella, A. (2005): «Memoria de género y biografía familiar», Revista Argentina de Sociología No 3: 99-116.

PINK, S. (2006): «Visual methods». In C. Seale, G. Gobo, J. Gubrium and D. Silverman. Qualitative Research Practice (London: Sage) (pp. 361-376).

PinK, S. (2007): Doing Visual Ethnography Second Edition, London, Sage.

PINK, S. (2001): Visual ethnography. Images, media and representation in research, London, Sage Publications.

Prosser, J. (1998): «The Status of Image Based Research.» in J. Prosser (ed) Image Based Research: A Sorcebook for Qualitative Researchers (pp. 97-112), UK, Falmer Press.

Prosser, J. (1992): «Personal Reflections on the Use of Photography in an Ethnographic Case Study», British Educational Research Association Journal 18(4): Available on line http://www.education.leeds.ac.uk/\%7Eedu-jdp/image/reflec.html Retrieved 26 June 2004.

Prosser, J. y Schwartz, D. (1998): «Photographs within the Sociological Research Process», en J. Prosser (ed) Image Based Research: A Sourcebook for Qualitative Researchers (pp. 115-130), UK, Falmer Press.

RASMUSSEN, K. (2004): «Places for Children - Children's Places», Childhood 11(2): 155173.

Reguillo Cruz, R. (2000): Emergencia de culturas juveniles. Estrategias del desencanto. Buenos Aires, Norma. 
RodríGuez Gutiérrez, M. (1995): «Testimonio y poder de la imagen», en Aguirre Baztán, A. (ed.), Etnografía. Metodología cualitativa en la investigación sociocultural, Barcelona, Editorial Boixareu Universitaria - Marcombo, pp. 237-247.

Rose, G. (2006): Visual Methodologies An Introduction to the Interpretation of Visual Materials, London: Sage Publications.

Schratz, M., y Steiner-LOFFLER, U. (1998): Pupils using photographs in school selfevaluation. In J. Prosser (Ed.), Image-based research. A sourcebook for qualitative researchers (235-251). London, Falmer Press.

Thomson, P. y GunTER, H. (2007): «The Methodology of Students-as-Researchers: Valuing and using experience and expertise to develop methods», Discourse Vol. 28: Routledge.

ThOMSON, P. AND GunTER, H. (2008): «Researching bullying with students: a lens on everyday life in an innovative school», International Journal of Inclusive Education 12(2): 185-200.

VERNIK, E. (2001): «Mirando políticos por T.V. Una etnografía del discurso político televisivo». Sociedad 10: 183-194.

WAGNER, J. (2000): «Contrasting images, complementary trajectories: sociology, visual sociology y visual research», Visual Studies 17(2): 160-171.

WAGNER, J. (2002): «Does image-based field work have more to gain from extending or from rejecting scientific realism? A review of Robert Coles, Doing Documentary Work and

Sarah Pink, Doing Visual Ethnography», Visual Sociology 16 (2), pp 7-21.

WANG, C., BurRIS, M. A. y PING, X. Y. (1996): «Chinese village women as visual anthropologists: a participatory approach to reaching policymakers», Social Science and Medicine 42(10): 1391-1400.

Young, L., y BARRET, H. (2001): «Adapting visual methods: action research with Kampala street children», Area, 33(2), 141-152. 


\begin{abstract}
ANEXO
Anexo 1: Consigna para el trabajo de Foto-elucidación y expresión de consentimiento de los y las estudiantes
\end{abstract}

Consigna para la toma de fotos

«Nos gustaría que me cuentes sobre vos y tu vida dentro y fuera de la escuela por medio de fotos»

\title{
Acuerdo para la entrega de rollos y próximo encuentro:
}

1. Te pedimos que tomes fotos los próximos 7 días a partir del día 21/06/07 y nos entregues la cámara descartable el día 27/06/07 para que revelemos el rollo.

2. El día ......... te entregamos las fotos reveladas y tenemos un encuentro para charlar sobre tus fotos.

Acuerdo entre la directora del proyecto, las investigadoras del equipo UBACyT (Proyecto S836) y ....................... para la toma y reproducción de imágenes

1. ................. (nombre del alumno/a) se compromete a sacar un ro1lo de 27 fotos durante 7 días consecutivos a partir del ................. y tener al menos un encuentro con la directora del proyecto o los miembros de su equipo para charlar sobre sus fotos.

2. La directora del proyecto y su equipo reconoce la propiedad intelectual de .................. (nombre del alumno/a) sobre las fotografías sacadas en el marco de su investigación.

3. A continuación ............ (nombre del alumno/a) expresará si autoriza o no a la directora del proyecto y a su equipo a usar sus imágenes en distintas publicaciones o situaciones: 


\begin{tabular}{|c|c|c|c|c|}
\hline \multirow[b]{2}{*}{ Uso de las imágenes } & \multicolumn{4}{|c|}{$\begin{array}{l}\text { Tipo de Autorización } \\
\text { (completar con una cruz la opción que corresponda) }\end{array}$} \\
\hline & $\begin{array}{l}\text { Autorizo que } \\
\text { la directora } \\
\text { del proyecto } \\
\text { y su equipo } \\
\text { usen cual- } \\
\text { quiera de mis } \\
\text { fotos }\end{array}$ & $\begin{array}{l}\text { Autorizo que la di- } \\
\text { rectora del proyec- } \\
\text { to y su equipo } \\
\text { usen todas las fo- } \\
\text { tos pero cuando } \\
\text { aparezcan perso- } \\
\text { nas sean «anoni- } \\
\text { mizadas» }\end{array}$ & $\begin{array}{l}\text { Autorizo que } \\
\text { la directora del } \\
\text { proyecto y su } \\
\text { equipo use } \\
\text { sólo las si- } \\
\text { guientes fotos: } \\
\text { (indicar núme- } \\
\text { ro) }\end{array}$ & $\begin{array}{l}\text { No autorizo } \\
\text { que directora } \\
\text { del proyecto } \\
\text { y su equipo } \\
\text { usen mis fo- } \\
\text { tos }\end{array}$ \\
\hline \multicolumn{5}{|l|}{$\begin{array}{l}\text { En exposiciones en jornadas, } \\
\text { congresos o reuniones científi- } \\
\text { cas nacionales }\end{array}$} \\
\hline \multicolumn{5}{|l|}{$\begin{array}{l}\text { En exposiciones en jornadas, } \\
\text { congresos o reuniones científi- } \\
\text { cas internacionales }\end{array}$} \\
\hline \multicolumn{5}{|l|}{$\begin{array}{l}\text { En artículos de revistas espe- } \\
\text { cializadas nacionales }\end{array}$} \\
\hline \multicolumn{5}{|l|}{$\begin{array}{l}\text { En artículos de revistas espe- } \\
\text { cializadas internacionales }\end{array}$} \\
\hline \multicolumn{5}{|l|}{$\begin{array}{l}\text { En artículos de revistas o diarios } \\
\text { de interés general nacionales }\end{array}$} \\
\hline \multicolumn{5}{|l|}{$\begin{array}{l}\text { En libros dedicados a la socio- } \\
\text { logía o a la educación }\end{array}$} \\
\hline \multicolumn{5}{|l|}{$\begin{array}{l}\text { En páginas web con contenido } \\
\text { académico }\end{array}$} \\
\hline $\begin{array}{l}\text { En muestras o exposiciones fo- } \\
\text { tográficas a realizar en la es- } \\
\text { cuela }\end{array}$ & & & & \\
\hline
\end{tabular}

4. La directora del proyecto y a su equipo se compromete a comunicar los resultados de su trabajo a ................ y a consultar con él/ella la publicación de alguna imagen por medios que no hayan sido explícitamente solicitados en este acuerdo.

5. El trabajo de la directora del proyecto y su equipo es de carácter confidencial y anónimo. En otras palabras no compartirá con nadie la información que resulte de las entrevistas y utilizaré nombres de fantasía en toda producción escrita vinculada a la escuela.

Nombre del alumno/a: Firma de directora del proyecto

Firma:

Buenos Aires, abril de 2007. 
